
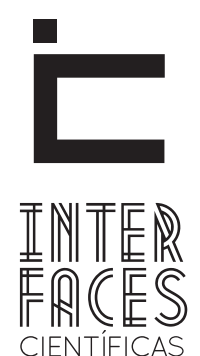

EDUCAÇÃO

ISSN IMPRESSO 2316-333X

E-ISSN 2316-3828

DOI 10.17564/2316-3828.2016v4n2p83-96

\title{
ARTICULAÇÕES E USOS DO MATERIAL DIDÁTICO DE ESPANHOL EM ESCOLAS PÚBLICAS ESTADUAIS DE SERGIPE: (DESJALINHAMENTOS COM AS POLÍTICAS PÚBLICAS DE ENSINO?
}

Sandro Marcío Drumond Alves Marengo ${ }^{1}$
Valéria Jane Siqueira Loureiro²

\section{RESUMO}

Este artigo trata de uma investigação que envolve os Livros didáticos de espanhol do Programa Nacional do Livro Didático (PNLD) do ano de 2012 e sua relação com os documentos de políticas públicas que regem o ensino do espanhol no Brasil. Os objetivos foram: levantar como se fez a escolha do livro didático de língua espanhola, fruto do PNLD 2012; apresentar como esses instrumentos são usados/manuseados pelos docentes nos espaços formais de aprendizagem; e verificar se há um alinhamento do preconizado nas Orientações Curriculares Nacionais para o Ensino Médio - Conhecimentos específicos de Espanhol (OCEM) e no Guia do Livro Didático (Guia do PNLD - Línguas
Estrangeiras Modernas), com as ações efetivas dos professores em seus contextos de trabalho. Foram realizadas entrevistas, de onde coletamos os dados para uma análise qualitativa. Nossas conclusões apontam para um desalinhamento expressivo entre o que está escrito e o que é feito na prática no ensino de espanhol em Sergipe.

\section{PALAVRAS-CHAVE}

Livros Didáticos. Língua Espanhola. PNLD. 


\section{ABSTRACT}

This article deals with an investigation involving spanish textbooks Programa Nacional do Livro Didático (PNLD) of 2012 and its relation to policy documents governing the teaching of Spanish in Brazil. The objectives were to raise as did the choice of textbook Spanish language, fruit of PNLD 2012; present how these instruments are used / handled by teachers in formal learning spaces; and check for alignment the invitation in the National Curriculum Guidelines for Secondary Education (Spanish OCEM- specific knowledge) and the Textbook Guide (PNLD- Guide Modern Foreign Languages), with the effective action of teachers in their contexts job. Interviews were conducted, where we collect the data for qualitative analysis. Our findings point to a significant misalignment between what is written and what is done in practice in teaching Spanish in Sergipe.

\section{KEYWORDS}

Textbooks. Spanish. PNLD.

\section{RESUMEN}

Ese artículo trata de una investigación que involucra los libros textos de español del Programa Nacional do Livro Didático (PNLD) del año de 2012 y su relación con los documentos de políticas públicas que rigen la enseñanza del español en Brasil. Los objetivos fueron: indicar como se hizo la elección del libro texto de lengua española, fruto del PNLD 2012; presentar cómo esos instrumentos son usados/manuseados por los docentes en los espacios formales de aprendizaje; y verificar si hay un alineamiento del preconizado por las Orientações Curriculares Nacionais para - Ensino Médio (OCEM- Conhecimentos específicos de Espanhol) y por el Guia do Livro Didático (Guia do
PNLD- Línguas Estrangeiras Modernas), con las acciones efectivas de los profesores en sus contextos de trabajo. Se realizaron entrevistas, de donde recolectamos los datos para un análisis qualitativo. Nuestras conclusiones apuntan que no hay alineamiento entre lo que se escribe y lo que se hace en la práctica en la enseñanza de español en Sergipe.

\section{PALABRAS- CLAVE}

Libros textos. Lengua española. PNLD. 


\section{CONSIDERAÇÕES INICIAIS}

0 ano de 2011 foi o primeiro em que as Línguas Estrangeiras/Adicionais foram incluídas no Programa Nacional do Livro Didático (PNLD). Nesse primeiro momento, foram avaliados livros para circulação no Ensino Fundamental. No ano seguinte, 2012, foram examinados os materiais para o Ensino Médio. 0 foco desse artigo é o Ensino Médio, uma vez que, por força da promulgação da Lei Federal no 11.161/2005, desde o ano de 2010, todas as escolas públicas estaduais da Educação Básica brasileira foram obrigadas a implementar a língua espanhola como opção de estudos para os alunos.

Frente a essas realidades tão recentes, tanto a da implementação do ensino da língua na rede pública quanto a da inserção das línguas estrangeiras/adicionais no PNLD, estudos são necessários para saber como a relação professor-livro didático está se desenvolvendo. 0 cerne de nossa investigação recai sobre o professor de língua espanhola na cidade de Aracaju.

Assim, delimitamos três colégios estaduais da cidade de Aracaju, no Estado de Sergipe, como campo de ação de nosso trabalho. Nossos objetivos, neste artigo, são: 1) levantar como se fez a escolha do livro didático de língua espanhola, fruto do PNLD 2012, que ora são utilizados nessas escolas; 2) apresentar como esses instrumentos estão sendo usados/manuseados pelos docentes nos espaços formais de aprendizagem; e 3) verificar se há um alinhamento do preconizado em duas documentações de políticas públicas no Brasil, as Orientações Curriculares Nacionais para o Ensino Médio - Conhecimentos específicos de Espanhol (OCEM) e Guia do Livro Didático (Guia do PNLD - Línguas Estrangeiras Modernas), com as ações efetivas dos professores em seus contextos de trabalho.

Para alcançar nosso intuito, apresentaremos algumas reflexões teóricas sobre o livro didático (LD) e seus usos em ambientes formais de aprendizagem e suas vinculações com os documentos de políticas pú- blicas que delimitamos. Em seguida, vamos expor os procedimentos metodológicos que nortearam a coleta e a extração dos dados obtidos para, então, apresentar os resultados gerados e as discussões sobre eles. Por fim, apresentaremos as nossas considerações finais.

\section{REFLETINDO SOBRE OS LIVROS DIDÁTICOS E SEUS USOS}

O Programa Nacional do Livro Didático (PNLD) é responsável por selecionar os livros didáticos (LD) considerados mais apropriados para a educação nas escolas da rede pública, isto é, tais materiais passam por um criterioso e sigiloso processo de seleção realizado pelo programa já mencionado, mais precisamente por professores da educação básica e superior que atuam como docentes das línguas estrangeiras em escolas públicas e universidades situadas nas diversas regiões geográficas do país.

Como resultado, após tal processo, se disponibiliza o Guia do Livro Didático (GLD), que, por sua vez, reúne as resenhas das coleções aprovadas. Como podemos notar, o GLD é um importante instrumento que tem por objetivo auxiliar o professor no processo de escolha a fim de que sejam capazes de selecionar, entre as opções que the são ofertadas, a coleção mais adequada para o seu contexto de ensino. O GLD assume uma importante função política ${ }^{1}$ uma vez que objetiva expor resenhas críticas que servem como orientações para a decisão da escolha das coleções de LD, aprovadas previamente em seleção de edital público do Governo Federal.

1. Quando nos referimos ao termo "política", estamos baseados nos preceitos de Secchi (2010). O autor em questão assume, em língua portuguesa, o termo "política" ao sentido expresso pelo termo policy do inglês, que expressa relação direta com a construção de medidas de orientações para a decisão e ação que afetam, de alguma forma, bens públicos ou a eles vinculados. 
Além disso, convém pontuar que as escolhas refletirão diretamente no campo da Educação, pois esses materiais, financiados pelo poder público, serão os usados nas salas de aula. As resenhas apresentam, segundo a apresentação do GLD do PNLD 2012:

\begin{abstract}
[...] os resultados do processo de análise que considerou os três volumes consumíveis do livro do aluno, os correspondentes Manuais do Professor e os respectivos CDs em áudio. Além disso, você encontra detalhes sobre essas coleções, os critérios gerais e específicos norteadores da análise, a reprodução da ficha utilizada na avaliação e um quadro comparativo das coleções. Esse conjunto está agrupado sob o título "Língua estrangeira no ensino médio: compromisso com a cidadania", que traduz a filosofia dos documentos norteadores do ensino médio, bem como o entendimento da equipe em relação ao papel do ensino da língua estrangeira na escola pública. (BRASIL, 2011b, p. 7).
\end{abstract}

Notamos, então, que há uma preocupação social com a inserção das disciplinas de línguas estrangeiras modernas no ensino médio. Além disso, há ainda uma consciência do amplo impacto que umLD, fruto do PNLD, pode provocar na educação linguística de uma língua estrangeira/adicional na educação básica. Assim, verificamos a importância de as línguas estrangeiras passarem a integrar o PNLD. Segundo “Trata-se, portanto, da inclusão da língua estrangeira numa política pública que, até então, atendia a quase todas as demais disciplinas do currículo escolar" (DAHER ET AL., 2013, p. 408).

A edição do PNLD 2012 teve 32 (trinta e duas) coleções didáticas inscritas para o ensino-aprendizagem de língua estrangeira/adicional, sendo 12 (doze) de espanhol e 20 (vinte) de inglês. Contudo, no total, apenas 10 (dez) foram selecionadas, sendo 3 (três) de espanhol e 7 (sete) de inglês (BRASIL, 2011b). No caso da língua espanhola, as coleções aprovadas foram $E l$ arte de leer español, (PICANÇO; VILLALBA, 2010), Enlaces (OSMAN ET AL., 2010) e Síntesis (MARTIN, 2010).

No que concerne ao processo de análise de tais coleções, evidenciou-se a importância do compromisso que a disciplina precisa assumir com relação à cidadania - compromisso esse que não se atém apenas ao ensino de uma língua estrangeira/adicional, mas sim a todas as disciplinas que compõem o currículo nesse nível de ensino. Isso porque cabe a cada uma das disciplinas:

[...]a partir de suas especificidades, delinear seu modo de participar da preparação básica para o trabalho, para a cidadania, para o aprimoramento da autonomia intelectual e do pensamento crítico do estudante, pautando-se sempre em valores éticos e humanos, tal como o proposto pela LDB 9394/96. (DAHER ET AL., 2013, p. 419).

Verificamos assim que os LD são instrumentos mediadores do trabalho do professor. Logo, refletir sobre eles também é um passo fundamental. Ainda segundo Daher e outros autores (2013), ao pensarmos em material didático é comum que, primeiramente, nos venha a ideia dos LD que costumeiramente são adotados como fonte fundamental de conteúdos e atividades no transcurso de uma disciplina.

Esses manuais, empregados em sala de aula, vinculados a estratégias usadas para um fim pedagógico específico, em determinados casos, são investidos de tanta importância que acabam se tornando a única referência para o planejamento e elaboração do curso e, nessas situações, o regente costuma apenas transpor para o plano de curso os conteúdos listados no índice do livro. Assim, vemos que:

\begin{abstract}
O caráter de autoridade do livro didático encontra sua legitimidade na crença de que ele é depositário do saber a ser decifrado, pois supõe-se que o livro didático contenha uma verdade sacramentada a ser transmitida e compartilhada. Verdade já dada que o professor, legitimado e institucionalmente autorizado a manejar o livro didático, deve apenas reproduzir, cabendo ao aluno assimilá-la. (SOUZA, 1999, p. 27).
\end{abstract}

Por isso, o LD tem sido foco, dentro das línguas estrangeiras modernas, de vários estudos que o situam para além das práticas pedagógicas. Daher e outros autores (2013) comentam sobre isso quando afirmam que: 
[...] de sua natureza dada, inicialmente, de modo um tanto ingênuo, como material de apoio ao ensino e à aprendizagem escolar, passa a ser visto como objeto que comporta visões de mundo, valores, formas epistemológicas de compreensão do saber científico das mais diversas disciplinas - e o que isso implica na relação escola-professor-saber-aluno -, e que, ao mesmo tempo, mobiliza um valor de mercado relevante para autores, editoras e demais empresas envolvidas na sua produção. (DAHER ET AL., 2013, p. 408).

Importante a menção feita sobre a mobilização do mercado editorial. Devemos ressaltar que, além das discussões educativas que envolvem os livros didáticos do PNLD, questões de ordem financeira também estão em jogo. "O expressivo volume de livros didáticos eu circula no Brasil, [...] resultante, sobretudo, do Programa Nacional do Livro Didático (PNLD) [...] comprovadamente situa o governo brasileiro como o maior comprador de livros do país" (CASSIANO, 2013, p. 169-170). Desse modo, as editoras desenvolvem, junto à preocupação de produção de livros didáticos que atendam os requisitos de parâmetros de qualidade constantes nas documentações que norteiam as políticas públicas de educação, um grande esforço para suas obras serem escolhidas uma vez que, do ponto de vista econômico, sua compensação é muito atrativa.

\begin{abstract}
No caso brasileiro, as políticas públicas adotadas pelo Estado com relação ao livro didático dão ao país uma particular isenção no contexto internacional. Amorim, ao caracterizar o Brasil em relação aos programas de livros escolares no mundo no início do século XXI, observa que o país é o terceiro em compras institucionais (os primeiros são China e Estados Unidos), e apresenta o PNLD como o maior programa de distribuição de livros didáticos do mundo. (CASSIANO, 2013, p. 173).
\end{abstract}

A partir de então, podemos pensar que uma política de supervalorização do livro didático se constitua de uma dupla face: uma, a rentabilidade econômica que ele gera no mercado editorial, a outra, uma espécie de "empoderamento" desse artigo frente a quaisquer outros tipos de materiais que possam ser desenvolvidos e aplicados em salas de aula de forma autônoma pelo professor. Assim, verifica-se que o LD é, comumente - e pelos diversos fatores já apontados, o único material didático utilizado em sala de aula pelos professores em geral (OLIVEIRA, 1986; FREITAG ET AL., 1989; LAJOLO, 1996) e, apesar da importância que ele possui nos contextos formais de aprendizagem, ocupando, inclusive, muitas das vezes o lugar central do ensino-aprendizagem, ele não pode suprir todas as necessidades e, portanto, não deve ser o único material usado nas aulas de língua estrangeira/ adicional (FERRO; BERGMAN, 2008).

Ademais, cabe destacar que, visando à diversidade do público alvo destinado e as variadas realidades do ensino e aprendizagem no Brasil, o LD pode e deve ser complementado com atividades, elaboradas utilizando outros tipos de materiais didáticos. Barros e Costa (2010, p. 88) definem material didático como:

\begin{abstract}
[...] qualquer instrumento ou recurso (impresso, sonoro, visual etc.) que possa ser utilizado como meio para ensinar, aprender, praticar ou aprofundar algum conteúdo. Sendo assim, enquadram-se nessa definição não só os manuais mencionados acima, ou apostilas, folhas de exercícios, testes, provas, mas também livros em geral, dicionários, áudios, vídeos, jornais, revistas, textos diversos, músicas, jogos etc. Cada um desses instrumentos tem suas especificidades e cabe destacar que materiais tais como vídeos, histórias em quadrinhos, músicas etc. só se caracterizam efetivamente como didáticos quando são usados com alguma finalidade pedagógica determinada pelo professor, o qual, na maior parte das vezes, prepara uma atividade para explorá-los.
\end{abstract}

Notamos, pois, que é necessário que o docente tenha autonomia e seja capaz de produzir tais materiais, de adequá-los conforme sua realidade, como também para um determinado objetivo pedagógico sempre que detecte a necessidade, e para isso ele conta com a infinidade de materiais didáticos disponíveis no mercado, assim como na internet. Cabe, então, uma reflexão sobre a relação entre o LD e os materiais complementares para o ensino de línguas. Costa (2011, p. 323), aponta que tanto um quanto outro "[...] deveria favorecer o desenvolvimento de capacidades básicas do pensamento autônomo e crí- 
tico [do aluno] [...]". Corroborando com o nosso pensamento, Ritcher (2005, p. 5) afirma que:

O lugar ocupado pelos livros didáticos na educação linguística pode variar consideravelmente, refletindo o tipo de relação mediadora que o material estabele ce entre o professor e o processo de ensino-aprendizagem, ou melhor, o maior ou menor grau em que o professor se subordina ao livro - variável esta até certo ponto influenciada pela abordagem básica do sistema educacional em que o profissional está inserido.

Logo, dentro da sala de aula, o professor deve exercer a postura de um agente transformador, formador e estimulador do desenvolvimento da autonomia intelectual, do pensamento crítico e da formação cidadã dos educandos. Sendo assim, notamos que ele é o principal agente causador da mudança em sua prática pedagógica. No que concerne ao ensino de línguas, se faz necessário que tais práticas sejam pensadas em diversas variáveis didáticas ao planejar, implementar e aperfeiçoar as atividades, a fim de auxiliá-lo na tarefa de transmitir o conteúdo de forma contextualizada e interdisciplinar, ampliando o conhecimento de mundo e o desenvolvimento das competências linguísticas dos educandos.

Isso porque, como evidenciam Barros e Costa (2010), baseados nas Orientações Curriculares para o Ensino Médio (OCEM), o papel educativo do ensino de língua estrangeira/adicional na escola não é mera aprendizagem de estrutura e gramática de uma língua, posto que

[...] um ensino "apenas linguístico ou instrumenta da Língua Estrangeira" não cumpre uma função educativa, já que "concentra mais esforços na disciplina/ conteúdo", ignorando os "valores sociais, culturais, políticos e ideológicos" do idioma (p. 90). Propõe-se, então, que a LE: amplie a leitura de mundo do aluno, a partir de uma perspectiva crítica; favoreça o contato com outras realidades e o conhecimento de outras culturas; propicie a apreensão do significado social da linguagem; e ofereça oportunidade de leitura, reconhecimento e discussão de diversos gêneros textuais e das práticas sociais às quais se vinculam. (BARROS; COSTA, 2010, p. 86-87).
Estabelece-se, desse modo, como em todo trabatho de educação linguística, um conjunto de decisões que são (ou devem ser) tomadas pelo docente, como a análise das necessidades do público-alvo, a definição de objetivos, a seleção e organização de conteúdos, a escolha e/ou modificação de materiais didáticos, e, por fim, a sua elaboração. Notamos, pois, que é necessário que o docente tenha autonomia e seja capaz de produzir tais materiais e/ou de adequá-los.

Ademais, cabe destacar que, visando a diversidade do público alvo e as variadas realidades do ensino e aprendizagem em território brasileiro, o LD pode e deve ser complementado com outras atividades, uma vez que ele é pensado em um plano macro ou, em outras palavras, para uma realidade global que acaba, portanto, desenhando um "mundo plástico" que só se realiza efetivamente dentro dos LD (SIQUEIRA, 2012). As OCEM, um dos documentos norteadores da política pública de ensino de línguas estrangeiras/adicionais, corroboram com essa ideia quando nos expõem que:

\begin{abstract}
É fundamental encarar o livro didático como um ponto de referência para o trabalho docente, como um recurso, não o único, facilitador do processo de ensinar e aprender, como um guia orientador geral, que auxilia na seleção e organização dos objetivos e conteúdos. Visto a partir dessa concepção, o livro didático é - ou deve ser - um recurso a mais, entre tantos, de que o professor dispõe para estruturar e desenvolver seu curso e suas aulas, mesmo quando ele é o responsável por sua elaboração/organização, o que pode constituir em alguns casos uma vantagem e em outros, uma desvantagem. (BRASIL, 2006, p. 154).
\end{abstract}

Desse modo, notamos a necessidade de que o docente adote uma postura mais autônoma em relação ao LD, refletindo, assim, sua visão como agente transformador e enxergando as múltiplas facetas que possuem os LD na educação.

\section{PROCEDIMENTOS METODOLÓGICOS}

Para a geração dos dados da nossa pesquisa, realizamos entrevistas orais, gravadas em áudio, com 
os professores de espanhol dos Colégios Estaduais Atheneu Sergipense, Djenal Tavares de Queiroz e Dom Luciano Cabral Duarte. Essas instituições foram escoIhidas levando em conta o critério de localização geográfica: todas estão localizadas no bairro São José, na cidade de Aracaju, Estado de Sergipe.

Os seis informantes entrevistados são todos do sexo feminino e têm idade entre 24 e 49 anos de idade. Três possuem graduação em Letras Espanhol, os demais em Letras Português-Espanhol, Pedagogia e Ciências Biológicas.

As entrevistas ${ }^{2}$ foram realizadas no período compreendido entre agosto de 2012 a dezembro de 2014 . As entrevistas possuem a duração entre 4 (quatro) minutos e 10 (dez) segundos e 11 (onze) minutos. 0 aparelho usado foi um modelo da Samsung GT-S3650. Todas as gravações foram armazenadas em CD e DV$\mathrm{D}-\mathrm{R}$ em formato mp3, mp4 e wav $\mathrm{w}^{3}$. As perguntas foram organizadas de modo a saber: de que modo foi realiza-

2. Os aspectos ético-legais envolvidos para a realização das entrevistas, bem como para a coleta e análise de dados, apresentados em Abreu (2014), foram respeitados.

3. As gravações e posterior transcrições das entrevistas, irão alimentar o banco de dados sobre o ensino do espanhol em Sergipe (BaDEnESE), que está sendo desenvolvido pelo projeto de pesquisa "Livros Didáticos de Espanhol (PNLD): Parâmetros e catalogação de (des)usos na Escola Pública [PVD35892015/edital n² 2/15/POSGRAP/COPES/UFS], vinculado ao grupo de pesquisas em análise e elaboração de materiais didáticos de línguas adicionais (GEMADELA/Diretório de Grupos de Pesquisas do CNPq). do o processo de escolha das coleções de LD (quem o fez, quais os critérios utilizados naquele momento para a delimitação de uma coleção de livros e o que levou à exclusão das demais) e como estava sendo o uso desses LD na sala de aula (aspectos positivos e negativos).

Para melhor disposição dos dados, construímos um quadro com os colégios delimitados (que representados, ao longo da análise, pelas etiquetas dispostas no quadro), os tópicos analisados e os dados gerados a partir das entrevistas. Nossa análise será de cunho qualitativo, pois iremos analisar e interpretar os dados com vistas a propiciar uma reflexão (CROKER, 2009) que consiga extrair alguma (ir)regularidade para que sejamos capazes de entender melhor a posição dos LD frente ao predisposto nas documentações que regem as políticas públicas que abarcam o ensino de línguas estrangeiras/adicionais - As OCEM e o PNLD.

\section{RESULTADOS E DISCUSSÕES}

Para iniciar nossas discussões vamos apresentar o quadro que resume as principais informações coletadas na entrevista e que são importantes para a concretização dos objetivos estabelecidos. Dessa forma, chegamos ao seguinte resultado: 
Quadro 1 - dados gerado das entrevistas (PNLD 2012)

\begin{tabular}{|c|c|c|c|}
\hline $\begin{array}{l}\text { COLÉGIOS ESTADUAIS/ } \\
\text { CRITÉRIOS ESTUDADOS }\end{array}$ & $\begin{array}{l}\text { ATHENEU } \\
\text { SERGIPENSE } \\
\text { (ATS) }\end{array}$ & $\begin{array}{l}\text { DOM LUCIANO } \\
\text { C. DUARTE } \\
\text { (DLC) }\end{array}$ & $\begin{array}{l}\text { DJENAL } \\
\text { TAVARES DE } \\
\text { QUEIROZ } \\
\text { (DTQ) }\end{array}$ \\
\hline $\begin{array}{l}\text { LIVRO } \\
\text { DIDÁTICO }\end{array}$ & El arte de leer. & Síntesis & El arte de leer. \\
\hline ESCOLHA DA COLEÇÃO & A professora. & A Direção. & A professora. \\
\hline $\begin{array}{l}\text { MOTIVAÇÃO/ } \\
\text { CRITÉRIOS DA ESCOLHA }\end{array}$ & $\begin{array}{l}\text { Exercícios mais funcio- } \\
\text { nais e menos estrutu- } \\
\text { rais; abordagem de tra- } \\
\text { balho com textos. }\end{array}$ & $\begin{array}{l}\text { Presença de quadros } \\
\text { gramaticais e exercí- } \\
\text { cios estruturais. Bom } \\
\text { manual do professor. }\end{array}$ & $\begin{array}{l}\text { Visita da editora e } \\
\text { autora à cidade a fim } \\
\text { de realizar a promo- } \\
\text { ção da coleção "El } \\
\text { arte de leer". }\end{array}$ \\
\hline $\begin{array}{l}\text { PROJETO } \\
\text { PEDAGÓGICO DA ESCOLA }\end{array}$ & Pouco conhece. & Pouco conhece. & Pouco conhece. \\
\hline $\begin{array}{l}\text { MATERIAL DE APOIO PARA } \\
\text { ESCOLHA }\end{array}$ & OCEM. & Manual do professor. & Nenhum. \\
\hline GUIA DO PNLD & $\begin{array}{l}\text { Desconhece. } \\
\text { Não utilizou. }\end{array}$ & $\begin{array}{l}\text { Desconhece. } \\
\text { Não utilizou. }\end{array}$ & $\begin{array}{l}\text { Desconhece. } \\
\text { Não utilizou. }\end{array}$ \\
\hline $\begin{array}{l}\text { MATERIAIS COMPLEMENTARES/ } \\
\text { SUPLEMENTARES }\end{array}$ & $\begin{array}{l}\text { Usa com pouca } \\
\text { frequência. }\end{array}$ & Não usa. & Uso predominante. \\
\hline $\begin{array}{l}\text { PAPEL DO } \\
\text { LIVRO DIDÁTICO }\end{array}$ & Centralizador. & Centralizador. & Inexistente. \\
\hline
\end{tabular}

Fonte: Dados da pesquisa.

Verificamos, em primeiro lugar, que a coleção de LD escolhida pelos informantes do ATS e DTQ foi $E l$ arte de leer español. No DLC, foi Síntesis - Curso de Lengua Española. 0 processo de escolha dos livros ocorreu no segundo semestre de 2011. As obras foram escolhidas de modo individual: ou pelo professor regente da disciplina (ATS e DTQ) ou pelo diretor da escola (DLC), sem nenhuma participação da coordenação pedagógica. No caso desse último colégio, o diretor justificou o fato de ter sido o responsável pela indicação do livro porque ainda não havia professores de espanhol na instituição ${ }^{4}$.

4. Para dar conta do cumprimento da lei 11.161/2005, que trata da oferta obrigatória de língua espanhola no Ensino Médio, o Governo de Sergipe por meio da Secretaria de Estado da Administração lançou o edital de processo seletivo simplificado №. 003/2010, no qual ofertavam 99 vagas para professores de Espanhol para cobrir a oferta inicial, obrigatória ou optativa de caráter emergencial e transitório, até a abertura do concurso público para a disciplina. Assim, entre janeiro de 2011 e setembro de 2012, as escolas contavam com professores que estavam sendo, aos poucos, contratados. No momento da escolha dos LD, no segundo semestre de 2011, o DLC ainda não havia recebido professores contratados de espanhol. 
As motivações para adoção das coleções foram diversas. No ATS, o fato de o livro ter mais exercícios funcionais que as demais coleções também aprovadas pelo PNLD 2012, apresentou-se como imperante. Segundo o informante do ATS, as outras duas coleções possuem uma abordagem bem mais estruturalista, destoando bastante da proposta do El arte de leer.

Outro critério também mencionado na entrevista foi o fato de o livro trabalhar com a abordagem de língua a partir de textos e análise compartilhada do aluno com o professor, isto é, apresenta um modelo de ensino-aprendizagem em que o professor interage com o aluno por meio das leituras, sendo, ainda segundo o informante, "muito mais profícuo porque instrumentaliza mais a língua”. Ressaltou, também, que o livro traz temas que tem proximidade com o mundo e a realidade dos alunos. 0 uso do termo "instrumentalizar" pelo informante nos chama atenção, uma vez que as OCEM nos aportam que

\begin{abstract}
A língua estrangeira não é simplesmente matéria escolar a ser aprendida, mas tem função educacional, e um dos seus papéis mais importantes, o de expor os alunos a outra língua a partir de uma óptica menos instrumental, poderá ajudar, entre outras coisas, a interferir positivamente na relação que os estudantes brasileiros guardam com a própria língua, em especial com a escrita. (BRASIL, 2006, p. 155).
\end{abstract}

No DLC, perguntamos quais teriam sido os motivos e quais os critérios adotados para a escolha de livros para uma disciplina que não era de domínio do informante. Obtivemos a resposta de que, como tinha filhos, ainda que não fosse professor formado na área, saberia o que deve conter um bom livro para o ensino de língua, seja materna ou estrangeira/adicional: (1) a presença de quadros gramaticais, que pudessem organizar a estrutura da língua (principalmente os verbos) para melhor apreensão e memorização dos alunos; e (2) a presença de muitos exercícios de completar lacuna para que os verbos e o vocabulário fossem bem memorizados e aprendidos. Além disso, também afirmou na entrevista que o livro devia ser pouco colorido e mais sério, pois língua estrangeira/adicional na escola já era "a hora do recreio" e deveria ser passada a ideia de que a disciplina era séria e importante.

Baseados nos dados apresentados, notamos que o sentido de ensino-aprendizagem de línguas estrangeiras/adicionais para a escolha do LD no DLC vai na contramão do que predispõem os documentos norteadores do ensino de espanhol na educação básica brasileira. Desta forma, Barros e Costa (2010) evidenciam o fato de que

\begin{abstract}
[...] um ensino "apenas linguístico ou instrumental da Língua Estrangeira” não cumpre uma função educativa, já que "concentra mais esforços na disciplina/ conteúdo", ignorando os "valores sociais, culturais, políticos e ideológicos" do idioma [...]. Propõe-se, então, que a LE: amplie a leitura de mundo do aluno, a partir de uma perspectiva crítica; favoreça o contato com outras realidades e o conhecimento de outras culturas; propicie a apreensão do significado social da linguagem; e ofereça oportunidade de leitura, reconhecimento e discussão de diversos gêneros textuais e das práticas sociais às quais se vinculam. (BARROS; COSTA, 2010, p. 86-87).
\end{abstract}

Essa perspectiva também é amplamente defendida e referendada pelos documentos oficiais de políticas públicas de ensino de línguas estrangeiras/adicionais, pois, nos Parâmetros Curriculares Nacionais (PCN) de línguas estrangeiras afirma-se que:

\begin{abstract}
Torna-se, pois, fundamental, conferir ao ensino escolar de Línguas Estrangeiras um caráter que, além de capacitar o aluno a compreender e a produzir enunciados corretos no novo idioma, propicie ao aprendiz a possibilidade de atingir um nível de competência linguística capaz de permitir-lhe acesso a informações de vários tipos, ao mesmo tempo em que contribua para a sua formação geral enquanto cidadão. (BRASIL, 2000, p. 26).
\end{abstract}

Assim, podemos notar que os critérios utilizados para a escolha dos LD no DLC, além de serem pouco profícuos, estão baseados em crenças e ideias que não mais figuram como pertinentes para a educação linguística com vistas aos múltiplos letramentos. 
Já no DTQ, o informante foi motivado por uma visita da editora e da autora da coleção escolhida à cidade de Aracaju, com a finalidade de realizar a promoção do LD. É importante mencionar que, tanto no DLC quanto no DTQ, os informantes que participaram da escolha dos livros não tinham formação na área de língua espanhola. Assim, tanto em um caso quanto no outro, verificamos que as motivações de escolha estão baseadas em aspectos que em nada se acercam do conhecimento do linguístico-estrutural ou funcional do processo de ensino-aprendizagem do espanhol.

Essa problemática se acerca a uma questão de política pública na formação de professores de espanhol no Brasil.

La formación de profesores de español es una de las deudas que el gobierno de Brasil tiene contraídas con la sociedad brasileña. Con el crecimiento súbito de la demanda del español, las carencias de profesorado se han hecho manifiestas, como reconoce el propio Ministerio de Educación brasileño, que ha llegado a habla de la necesidad de 210.000 profesores de español si se declara la obligatoriedad del español en la enseñanza no universitaria. Esta cifra, siendo abultada, no resulta descabellada teniendo en cuenta que esa obligatoriedad podría afectar a más de cinco millones de estudiantes en todo el país. (FERNÁNDEZ, 2005, p. 30).

Acreditamos ser de suma importância considerar a questão quantitativa apresentada, uma vez que, com a promulgação da Lei Federal $n^{0} 11.161 / 2005$, houve a obrigatoriedade de inclusão da língua espanhola no currículo do Ensino Médio em escolas públicas e privadas em todo o Brasil. Com sua vigência ficou estabelecido nacionalmente que o ensino do espanhol, de oferta obrigatória pela escola e de matrícula facultativa para o aluno, seria implantado gradativamente, nos currículos plenos do Ensino Médio ${ }^{5}$, cuja conclusão do processo deveria ser realizada no prazo máximo de 5 (cinco) anos, a partir da publicação da citada lei.

Dessa forma, como mostram os nossos dados, verificamos que, na capital de Sergipe, nem todas as

5. Esse dispositivo encontra-se no Artigo $1^{\circ}$ da Lei $11.161 / 2005$. escolas públicas estavam plenamente alinhadas com as exigências legais: ou estavam sem professor, como vimos no DLC, ou com professores sem a devida habilitação, como no DTQ.

Em sequência, questionamos os informantes sobre quais materiais e leituras teriam servido de base para auxiliar na escolha do LD. Todos foram unânimes em responder que usaram o "bom senso" e "os anos de magistério na educação básica" para realizar tal tarefa. Somente o informante do ATS agregou também ter usado, ainda que pouco, o conhecimento que tinha do conteúdo das OCEM. Ao perguntarmos sobre o alinhamento do LD escolhido com o projeto pedagógico da escola, os informantes afirmaram que o conheciam pouco já que isso era de alçada da Secretaria de Educação (SEED-SE). No entanto, afirmaram que as práticas pedagógicas do colégio sempre foram estipuladas pelos próprios professores e que o livro de espanhol escolhido (que era uma novidade no momento) era bem parecido com os livros de inglês que suas escolas adotavam antes do PNLD 2012.

Em seguida, perguntamos sobre o guia do PNLD e a leitura do guia como referência para auxílio na escolha. Todos os informantes confirmaram que não receberam fisicamente nenhum guia do PNLD de línguas estrangeiras, nem tampouco a indicação de que ele estaria disponível na página da internet do Fundo Nacional de Desenvolvimento da Educação (FNDE) e que, por isso, não realizaram a leitura do mesmo. Nesse momento, perguntamos se eles tiveram indicações de leitura do guia do PNLD no pacote de coleções que receberam para análise na escola. Todos os informantes afirmaram que só receberam duas coleções de livros na escola (Síntesis e El arte de leer) e, portanto, diante das duas coleções, o trabalho de escolha não era tão difícil. Todos os informantes afirmaram que levaram um pouco mais de meia hora para escolher a coleção a ser adotada.

Alguns pontos são merecedores de atenção a partir dos dados expostos. 0 que chama atenção foi o fato 
de o próprio diretor desconhecer o projeto pedagógico da escola. Isso demonstra uma desarticulação entre os documentos que regem as políticas públicas de ensino e seus usuários (ou executores). Tomamos como muito grave a afirmação de que é da ordem somente da Secretaria de Educação o fato de conhecer as diretrizes mínimas que regem o funcionamento do ensino de uma escola. Está evidente que, a partir desses dados, a prática é desvinculada da teoria. Além disso, é muito claro que os gestores desconhecem os parâmetros mínimos oficiais que estão regendo a política educacional de suas instituições.

Projeto Pedagógico [...] é um instrumento teórico-metodológico que visa ajudar a enfrentar os desafios do cotidiano da escola, só que de uma forma refletida, consciente, sistematizada, orgânica e, o que é essencial, participativa. É uma metodologia de trabalho que possibilita re-significar a ação de todos os agentes da instituição. (VASCONCELLOS, 1995, p. 143).

0 desconhecimento dos princípios que norteiam dada instituição, segundo os termos de Vasconcellos (1995), impede que os desafios cotidianos da escola sejam enfrentados (e superados) a partir de uma reflexão crítica e participativa. É de suma importância que o professor conheça o projeto pedagógico porque, por meio dele, consegue tornar-se capaz de compreender a sistematização de um processo de planejamento participativo. Ele é, então, a base da escola, pois define desde os conteúdos ensinados na sala de aula até como agir com eventuais problemas de gestão. Trata-se de um conjunto de elementos orientadores de todas as ações da comunidade escolar.

Sendo assim, não se tem precisão se o LD adotado pelo colégio é compatível ou não com o projeto pedagógico. No entanto, todos os informantes insistem em um paradoxo: dizer que a abordagem da escola é a mesma abordagem do livro. Dessa feita, os dados indicam a possibilidade de que se opere uma descentralização de ações que podem acabar por gerar o isolamento e a falta de diálogo que deixam de possibilitar, por exemplo, uma aprendizagem que ultrapasse os limites do senso comum e das escolhas pessoais em prol da troca do conhecimento entre áreas e das escolhas em conjunto. Isso é importante uma vez que, nas próprias diretrizes do GLD,

\section{Ao escolher os livros didáticos para o ensino médio, é importante que o professor identifique, nos textos das resenhas das obras, indicativos que se coadunem com os estabelecidos acima, visando estabelecer uma aproxima- ção o mais efetiva possível entre o livro didático e o pro- jeto político-pedagógico da escola. (BRASIL, 2011a, p. 9).}

É tarefa dos professores, conjuntamente com a equipe pedagógica, analisar as resenhas e as indicações contidas no GLD para escolher adequadamente os LD. Além disso, expõe que o material adotado deve ser, minimamente, adequado ao projeto político-pedagógico da escola, ao aluno e professor, e à realidade sociocultural das instituições. Se o GLD de línguas estrangeiras tivesse sido lido, muitos aspectos que não foram apontados nas entrevistas certamente teriam sido levados em conta, pois a seguinte indicação é feita

\begin{abstract}
Professor, como você bem sabe, a responsabilidade da escolha do livro didático de língua estrangeira requer da equipe envolvida a compreensão de que esse processo implica compromisso didático-pedagógico. Esse compromisso, ao levar em consideração as circunstâncias histórico-sociais do seu grupo, exige cuidado nas discussões, a fim de que não se trate como homogêneo e simples aquilo que é naturalmente heterogêneo e complexo: o processo de ensino e aprendizagem é dinâmico e plural. Por esse motivo, o livro didático deve ser entendido como uma produção que está vinculada a valores, posições ideológicas, visões de língua, de ensino de língua, de aluno, de professor, e de papel das línguas estrangeiras na escola. Assim, a escolha do livro didático de língua estrangeira faz parte da definição dos rumos do ensino médio público brasileiro. (BRASIL, 2011b, p. 8).
\end{abstract}

Então, pelo que constatamos, praticamente nada do que se preconiza no GLD do PNLD 2012 foi, na prática, realizado nas escolas em questão, no momento de decidir qual coleção seria adotada.

No que tange à formulação de materiais extras ao LD, somente o informante do DTQ costuma utilizá- 
-los com bastante frequência. Isso porque, na entrevista, afirmou não usar o livro porque, apesar de tê-lo escolhido ${ }^{6}$, não sabia como operar com um livro que não tinha exercícios estruturais e quadro de verbos. Portanto, usava uma apostila de um curso que tinha feito anos atrás.

Sabemos que nenhum LD deve ser considerado perfeito (ANSARY; BABAII, 2002) e, portanto, o professor deve ter a capacidade de manuseá-lo para atender as suas necessidades. Contudo, os dados gerados nas entrevistas apontaram que o LD possuía um papel centralizador no planejamento e desenvolvimento das aulas no ATS e DLC. Como no DTQ o informante usava cópias de uma apostila, o LD era inexistente dentro da sala de aula ${ }^{7}$. Essas constatações contrariam o posicionamento de Cunningsworth (1995), que defende que o livro deve estar a serviço dos professores e dos alunos e não o contrário.

Esses dados também são preocupantes porque verificamos o papel centralizador do LD no processo de ensino-aprendizagem de espanhol nas aulas desses colégios. Entendemos que os materiais didáticos são instrumentos mediadores do trabalho do professor. Não estamos afirmando, no entanto, que o LD seja o elemento mais essencial em contextos de ensino-aprendizagem. Nesse ponto, destacamos o alinhamento de nosso posicionamento com Drumond e outros autores (2014, p. 48) ao afirmarem que um dos pontos que deveria ser tratado, para melhorar o processo de ensino-aprendizagem de línguas na escola, é o “[...] trabalho de desmistificar a centralização dada ao livro didático nos contextos formais de aprendizagem de línguas em prol da valorização da prática docente. Afinal, o melhor 'material' didático em sala de aula sempre foi (e deve ser) o professor."

6. Convém lembrar que, além de não ter formação na área, o informante escolheu o LD por conta da visita da editora e da autora à cidade de Aracaju.

7. Essas constatações também foram comprovadas em outro momento da pesquisa realizada, quando se procedeu a um conjunto de observações das aulas. Contudo, o nosso foco nesse trabalho não é esse. Estamos centrados somente nos dados gerados nas entrevistas.
Assim, além do tratamento dispensado à própria forma de atuação do docente, analisar o livro adotado é um aspecto relevante para que pensemos o aprendizado da língua espanhola. Refletir sobre sua seleção é um passo fundamental, pois devem ser levados em consideração elementos coerentes com os propósitos do professor, com as necessidades e objetivos dos alunos, tendo sempre em vista as diretrizes indicadas pelas leis e pelos documentos que regem a educação brasileira (como os PCN e as OCEM).

\section{CONSIDERAÇ̃̃ES NEM TÃO FINAIS...}

Ao levantar como se foram feitas as escolhas dos livro didáticos de língua espanhola, fruto do PNLD 2012, nas escolas delimitadas, verificamos que muitos aspectos importantes, tais como a reflexão do que é ensinar língua e de como essa perspectiva deve ser alinhada ao contexto sócio-cultural da comunidade escolar - promovido e disseminado pelo projeto pedagógico da escola, foram levados em conta de modo superficial e pouco estruturado. A falta de leitura das indicações relevantes do GLD do PNLD 2012 contribuíram isso. Dessa forma, destacamos a importância da disseminação deste Guia para que as escolhas sejam feitas de modo adequado e que possam proporcionar mais que uma simples eleição de material, mas condições propícias para que se reflita o que se tem e o que se quer ensinar na escola.

A partir dos dados apresentados, também fomos capazes de ver que, apesar de a escola adotar um LD fruto do PNLD 2012, os professores ainda não sabem como manusear este instrumento sem conferir uma autoridade de extremos a ele: ou é o centro do processo de ensino-aprendizagem de língua espanhola, ou é nulo nesse mesmo sistema.

A superioridade do LD frente à autonomia do professor em contextos formais de ensino nos direciona a uma reflexão sobre os componentes curriculares dos cursos de licenciatura. Por quê nossos professores 
não estão sabendo posicionar-se frente ao LD? Que elementos estão corroborando para a pouca autonomia do professor de língua espanhola no que tange o uso de materiais complementares em seu ofício? Como estão organizados os componentes curriculares, nos cursos de licenciatura, que tratam de materiais didáticos e avaliação? Essas são algumas dúvidas que surgem após as constatações a que chegamos a partir dos dados gerados.

Logo, por meio do demonstrado neste artigo, podemos afirmar que, apesar de haver poucos pontos de convergência entre os documentos de políticas públicas que abarcam o ensino de língua espanhola, há um desalinhamento expressivo entre o que está preconizado nas OCEM e no GLD do PNLD 2012 com as ações efetivas dos professores em seus contextos de trabatho. Desse modo, há um caminho longo a percorrer na busca de um alinhamento que venha a proporcionar melhores condições ao lugar que o espanhol ocupa na educação básica brasileira.

\section{REFERÊNCIAS}

ABREU, Ricardo Nascimento. Aspectos legais envolvidos na coleta de dados lingüísticos. In: FREITAG, Raquel Meister Ko. Metodologia de coleta e manipulação de dados em sociolinguística. São Paulo: Blucher, 2014. p.7-17.

ANSARY, H.; BABAII, E. Universal characteristics of EFL/ESL textbooks: a step towards systematic textbook evaluation. In: The Internet TESL Journal, v.8, n.2, fev. 2002.

BARROS, Cristiano Silva; COSTA, Elzimar Goettenauer de Marins. Elaboração de materiais didáticos para o ensino de espanhol. In: BARROS, Cristiano Silva de; COSTA, Elzimar Gottenauer de Martins.Educação. Coleção Explorando o Ensino. v.16. Espanhol: ensino médio. (Org.). Brasília: MEC/ Secretaria de Educação Básica, 2010.
BRASIL. Parâmetros curriculares nacionais: ensino médio. Brasília: MEC, Secretaria de Educação Básica, 2000.

BRASIL. Lei $\mathbf{n}^{0}$ 11.161, de 5 de agosto de 2005. Disponível em: <http://www.camara.gov.br>. Acesso em: 29/10/2015

\section{BRASIL. Orientações curriculares para o ensino médio. Linguagens, códigos e suas tecnologias. Conhecimentos de Espanhol. Brasília: MEC, Secretaria de Educação Básica, 2006.}

BRASIL. Guia de livros didáticos: PNLD 2012:

Apresentação. Brasília: MEC/SEB, 2011a.

BRASIL. Guia de livros didáticos: PNLD 2012: Língua Estrangeira Moderna. Brasília: MEC/SEB, 2011b.

CASSIANO, Célia Cristina de Figueiredo. 0 mercado do livro didático no Brasil do século XXI. São Paulo: Unesp, 2013.

COSTA, Elzimar Goettenauer de Marins.Lugar de aprender língua estrangeira é na escola: reflexões em torno do PNLD 2011. Revista Letras, v.21, n.42, Santa Maria, , 2011. p.315-340.

CROKER, Robert A. An Introdution to qualitative research. In: HEIGHAM, Juanita; CROKER, Robert A. Qualitative research in Applied Linguistics: a pratical introduction. Great Britain: Palgrave Macmilian, 2009.

CUNNINGSWORTH, A. Choosing your coursebook. Great Britain: Heinemann Publishers, 1995.

DAHER, Del Carmen; FREITAS, Luciana Maria Almeida de; SANT’ANNA, Vera Lúcia de Albuquerque. Breve trajetória do processo de avaliação do livro didático de língua estrangeira para a educação básica no âmbito do PNLD. Eutomia, n.11, v.1, Recife-PE, 2013. p.407-426. 
DRUMOND, Sandro M., PELUFFO, Alfonso R. C., JESUS, Elidiane S., MENDONÇA, Fernando C. \& BORGES, Manuela C. Nada se cria? Nada se perde. Tudo se transforma! A natureza da experiência do PIBID espanhol em Sergipe como valorização da prática docente. Trilhas da formação docente, v.1, n.1, 2014. p.43-49.

FERNÁNDEZ, F. M. “El español en Brasil” In: SEDYCIAS, J. (Org). 0 ensino do espanhol no Brasil - passado, presente, futuro. São Paulo: Parábola, 2005. p.14-34.

FERRO, Jeferson; BERGMANN, Juliana Cristina Faggion. Produção e avaliação de materiais didáticos em língua materna e estrangeira. In: Metodologia do ensino de língua portuguesa e estrangeira. Curitiba: Ibpex, 2008. p.19-31.

FREITAG, Bárbara; COSTA, Wanderley F. Da; MOTTA, Valéria R. 0 livro didático em questão. São Paulo: Cortez, 1989.

LAJOLO, Marisa. “LIVRO DIDÁTICO: um (quase) manual de usuário. Em Aberto, v.16, n.69, 1996. p.3-9.

MARTIN, Ivan. Síntesis, curso de lengua española. São Paulo: Ática, 2010.

OLIVEIRA, Alaíde Lisboa de. 0 livro didático. Rio de Janeiro, 1986.
OSMAN, Soraia; ELIAS, Neide; REIS, Priscila; IZQUIERDO, Sonia; VALVERDE, Jenny. Enlaces. Español para jóvenes brasileños. São Paulo: Macmillan, 2010.

PICANÇO, Deise Cristina de Lima; VILLALBA, Terumi Koto Bonnet. El arte de leer español. Curitiba: Base, 2010.

RITCHER, M. G. O material didático no ensino de línguas. Revista Linguagem e Cidadania, 14.ed. Santa Maria, jul-dez. 2005.

SECCHI, Leonardo. Políticas públicas: conceitos, esquemas de análise, casos práticos. São Paulo: Cengage Learning, 2010.

SIQUEIRA, Sávio. Se o inglês está no mundo, onde está o mundo nos materiais didáticos de inglês? In: SCHEYERL, Denise; SIQUEIRA, Sávio (Org.) Materiais didáticos para o ensino de línguas na contemporaneidade: contestações e proposições. Salvador: EdUFBA, 2012. p.311-353.

SOUZA, Deusa Maria. Autoridade, autoria e livro didático. In: CORACINI, Maria José Rodrigues Farias. Interpretação, autoria e legitimação do livro didático. Campinas: Pontes, 2011. p.27-31.

VASCONCELLOS, C. S. Planejamento: plano de ensino-aprendizagem e Projeto Educativo. São Paulo: Libertad, 1995. 